\title{
ON THE DETERMINATION OF CITRIC ACID IN LEMON-JUICE.
}

By Rowland Williams, F.I.C., F.C.S.

(Read at the Meeting, December, 1888.)

The general chemistry of citric acid has already been so ably dealt with in the excellent and exhaustive papers by $\mathrm{R}$. Warington (Journal of the Chemical Society, vol. xxviii., p. 925), and by B. J. Grosjean (Journal of the Chemical Society, vol. xliii., p. 331), that it is not necessary for me to dwell at any length on that part of the subject. I may say at once that my special object in bringing this matter before the Society of Public Analysts is to promote a discussion among the members, with the view to attain, if possible, a standard process for estimating the citric acid in lemon-juice, as, in the face of recent improvements in analytical chemistry, this question certainly deserves further 
consideration-former methods being more or less unreliable, owing to the unsatisfactory nature of the indicators employed.

Litmus, logwood, and cochineal solutions, all of which have, I believe, been used in the past, are unsuitable indicators, while litmus-paper is, for a reason which will presently appear, not very much better. Samples of lemon-juice are sometimes sent to my laboratory for examination by calico-printers and others, and my results nearly always come out lower than those of Mr. G. H. Ogston, upon whose certificate, lemonjuice is, I understand, generally sold in this country.

These discrepancies having occurred rather frequently, I communicated with $\mathrm{Mr}$. Ogston, in order, if possible, to come to an understanding as to the method to be adopted in the analysis of future samples, so as to avoid any further differences between our results.

In the course of his reply Mr. Ogston said, "The process agreed upon for the commercial analysis of lemon-juice is titration by carbonate of soda solution, using litmus-paper as indicator."

Mr. Ogston then points out certain precautions necessary to be observed, and admits that the exact point at which to cease adding the carbonate of soda is difficult to see, and can be determined only after a good deal of experience.

I was rather surprised to hear of an analyst employing carbonate of soda in estimations of citric acid. I myself use pure caustic soda solution, which I find to be preferable in every respect.

Litmus-paper is also, in my opinion, a very unsatisfactory indicator, as it is affected to a considerable extent by normal citrate of soda-the real end reaction being thus difficult to tell with accuracy.

It is a well-known fact that citrate of soda solution, according to its degree of dilution, turns pink litmus-paper more or less blue, and it becomes, therefore, to a certain extent a matter of chance as to what excess of soda must be added when litmuspaper is used as an indicator.

In order to overcome this difficulty it is, I believe, customary to ascertain the exact strength of the alkali by means of pure citric acid and pale litmus-paper, taking as nearly as possible the same shade of blue for the end reaction, both in standardising and in performing the actual analysis; but even using every precaution, $I$ find this plan to be unsatisfactory, in addition to being very tedious.

In estimating citric acid I have long since discarded litmus as an indicator in favour of phenolphthalein, as recommended by R. T. Thomson (Journal of the Society of Chemical Industry, vol. vi., p. 195) and other chemists. This latter indicator I have proved to be quite unaffected by citrate of soda, whereas this salt is distinctly alkaline to litmus, as already mentioned. The end of the reaction is also seen with the greatest precision when phenolphthalein is used, one drop of normal caustic soda solution in excess being sufficient to produce an unmistakable change of colour. No reliance can, of course, be placed on results obtained by titrating with either hydrate or carbonate of sodium in the presence of mineral acids, but in their absence neutralisation with alkali gives a fairly accurate idea of the amount of citric acid present, especially in concentrated lemon-juice. 
In the presence of other acids which might interfere with the ordinary soda test it is necessary to employ the calcium chloride process described in Mr. Warington's paper.

The plan which I adopt in the analysis of concentrated lemon-juice is as follows : The specific gravity is first taken at $60^{\circ}$ Fah. For this purpose some analysts employ a special hydrometer, termed a "citrometer," on the scale of which every 004 above unity is equivalent to one degree.

As is the case with so many commercial products, the density indication is of little or no value, unless the lemon-juice is free from adulteration. Nevertheless, it is customary to state the "citrometer" indication on commercial certificates. Indeed, many calico-printers in my district actually buy according to the "citrometer" degrees, without paying much attention to the proportion of citric acid present, and thus become ready victims to the wiles of unscrupulous drysalters. In order to determine the total acidity of the juice, I dilute 1,000 grains measure of the sample to 10,000 grains with water in a stopped measuring-flask, and take one-tenth of the whole (equivalent to 100 grains of the original juice) for titration with alkali. This aliquot portion is placed in a large porcelain basin, and diluted with water until the liquid is of a pale yellow shade, and after the addition of a few drops of alcoholic phenolphthalein solution, normal caustic soda solution is run in from a burette until a rose colour appears. In order to avoid any possible chance of error, I always perform the entire process in duplicate. Two determinations of the total acidity should agree within two grains of normal soda solution. The results are calculated into ounces of citric acid per gallon.

As a confirmatory test, another carefully measured portion of the sample may be taken, and without any previous dilution, neutralised with the requisite amount of caustic soda. Rather more than the calculated quantity of a 20 per cent. solution of calcium chloride is next added, and the whole heated in a salt bath for some time.

The calcium citrate is filtered off, washed slightly with boiling water, the filtrate concentrated to a small bulk, taking care to keep the solution neutral, and again filtered. If necessary, the filtrate is again concentrated, and any precipitate which comes down filtered off through a very small filter. The precipitates are gently ignited in a platinum crucible, in order to convert the calcium citrate into calcium carbonate, which is then decomposed by excess of normal hydrochloric acid, filtered and titrated back with normal caustic soda.

When testing genuine samples of lemon-juice I have generally found this process to give figures agreeing fairly well with those obtained by direct titration with soda, the results being in most cases rather lower, owing to part of the total acidity being due to organic acids, other than citric, which do not form an insoluble lime salt.

I have tried the carbonate of soda method used by Mr. Ogston, in comparison with my ordinary process, on several samples of lemon-juice, some of which were taken from pipes imported from abroad, while the others were prepared from lemons pressed and concentrated in my own laboratory. The figures obtained will be found in the accompanying table:- 
Ounces of Citric Acid per Gallon.

\begin{tabular}{|c|c|c|c|c|c|c|c|c|}
\hline & & & & & & $\begin{array}{c}\text { NaHO } \\
\text { Method. }\end{array}$ & $\begin{array}{l}\mathrm{Na}_{2} \mathrm{CO}_{3} \\
\text { Method. }\end{array}$ & $\begin{array}{c}\mathrm{CaCl}_{3} \\
\text { Method. }\end{array}$ \\
\hline \multicolumn{6}{|c|}{ Foreign Samples. } & \multirow{7}{*}{$\begin{array}{l}68 \cdot 24 \\
63 \cdot 48 \\
61 \cdot 80 \\
62 \cdot 88 \\
60 \cdot 86 \\
66 \cdot 74\end{array}$} & \multirow{7}{*}{$\begin{array}{l}69 \cdot 42 \\
64 \cdot 56 \\
62 \cdot 55 \\
63 \cdot 96 \\
61 \cdot 84 \\
67 \cdot 88\end{array}$} & \multirow{7}{*}{$\begin{array}{l}64 \cdot 12 \\
58 \cdot 98 \\
58 \cdot 24 \\
60 \cdot 14 \\
57 \cdot 98 \\
64 \cdot 92\end{array}$} \\
\hline No, 1 & .. & .. & . & . & .. & & & \\
\hline No. 2 & . & .. & . & $\cdots$ & $\cdots$ & & & \\
\hline No. 3 & . & .. & .. & .. & . & & & \\
\hline No, 4 & . & .. & . & . & .. & & & \\
\hline No. 5 & .. & $\ldots$ & . & . & .. & & & \\
\hline No. 6 & . & . & . & . & . & & & \\
\hline \multicolumn{6}{|c|}{ Laboratory Samples. } & \multirow{4}{*}{$\begin{array}{l}94 \cdot 32 \\
63 \cdot 36 \\
75 \cdot 48\end{array}$} & \multirow{4}{*}{$\begin{array}{l}94 \cdot 56 \\
64 \cdot 32 \\
76 \cdot 20\end{array}$} & \multirow{4}{*}{$\begin{array}{l}94 \cdot 08 \\
62 \cdot 52 \\
75 \cdot 60\end{array}$} \\
\hline No. 1 & $\ldots$ & $\ldots$ & . & . & . & & & \\
\hline No. 2 & .. & .. & . & $\ldots$ & .. & & & \\
\hline No. 3 & . & . & . & . & . & & & \\
\hline
\end{tabular}

These experiments show plainly that titration with carbonate of soda and litmuspaper invariably gives higher results than titration with caustic soda and phenolphthalein. I may say, in passing, that my carbonate of soda results, although so much higher than the caustic soda figures, are lower than those obtained by Mr. Ogston in testing duplicate samples.

Pure Citric Acid.-We now come to the consideration of the respective values of normal carbonate and caustic soda solutions, when titrated against pure citric acid, as upon this the value of the process entirely depends. For this purpose I obtained samples of citric acid from seven different manufacturers. Very accurately weighed quantities of each were carefully titrated with pure normal caustic and carbonate of soda, using alcoholic solution of phenolphthalein and litmus-paper as the respective indicators. All the experiments were done in duplicate. In the following table are given the number of grains of the seven samples respectively, neutralised by one hurdred grains of normal caustic and carbonate of soda solutious :-

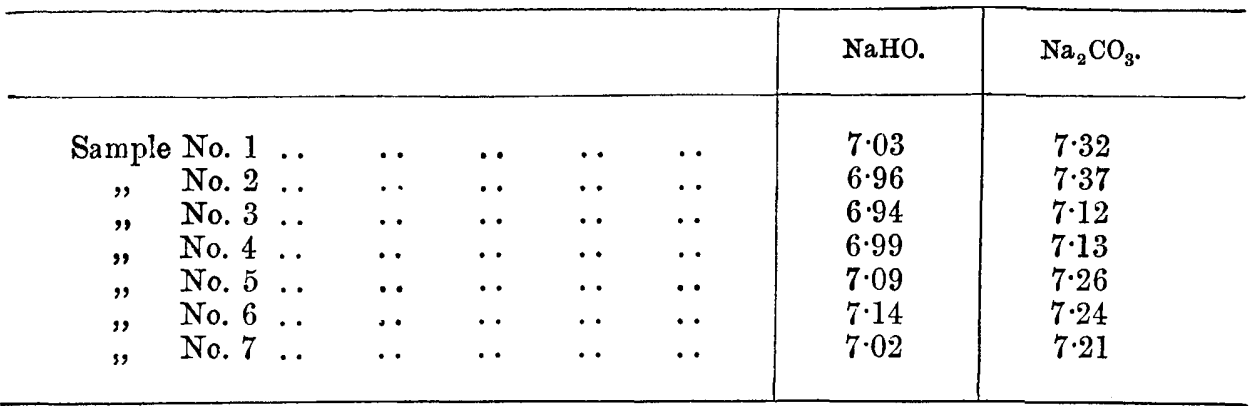

On averaging these figures, it will be seen that 100 grains normal caustic soda equal 7.02 grains citric acid, while 100 grains normal carbonate of soda equal $7 \cdot 23$ grains citric acid. For all practical purposes, the 7.02 grains may be regarded as 7 grains, the slight difference being, no doubt, due to the presence of traces of impurities in some of the samples of citric acid. This result would then agree exactly with the figure demanded by theory.

The accuracy of titrations made with caustic soda, using phenolphthalein as in- 
dicator, having thus been proved beyond doubt in the case of citric acid, it seems undesirable to employ carbonate of soda in the analysis of lemon-juice, as the estimation then occupies so much longer time, besides not giving such reliable results. I would suggest, therefore, that the citric acid in lemon-juice should in future be determined by titration with caustic soda and phenolphthalein in the absence of interfering bodies, the result to be confirmed, if necessary, by the application of the calcium chloride test previously described.

In conclusion, I should like to add that the calcium chloride method indicated $99 \cdot 4$ per cent. of citric acid, when tried on a portion taken from the mixture of the seven samples of citric acid already referred to.

\section{Discussion.}

The President said that he was glad to find that Mr. Rowland Williams appreciated the use of phenolphthalein as an indicator. He thought that the tendency was to use phenolphthalein more and more in all cases in which it was suited for the purpose - that is, where a weak acid was to be determined and the absence of carbonic acid could be ensured. He had no doubt that the process of titrating citric acid and lemonjuice by caustic alkali and phenolphthalein was novel so far as Mr. Williams was concerned; but it had been in constant use for some years, to his (the President's) knowledge, in several laboratories where such essays were required, and the process was fully described in his "Commercial Organic Analysis," vol. i. Phenolphthalein always gave very satisfactory results where the colour could be seen; but in the case of very dark juices it sometimes became necessary to have an outside indicator, in which case very delicate litmus-paper, made by brushing a neutral solution of litmus on to white writing-paper, not absorbent paper, was the best substitute for it. Congo-red paper would probably also be valuable. It was disheartening to learn that chemists of repute were still content to titrate lemon-juice with an alkaline carbonate and litmus. He was not surprised that Mr. Williams's results did not agree with those who employed so antiquated and unsatisfactory a process, and there could be no doubt on which side the truth lay. In titrating with phenolphthalein there was one direction in which he thought an improvement might be made, and that was to use a standard solution of baryta instead of caustic soda. Baryta had the advantage that it was certain to be free from carbonic acid, which, of course, was not the case with caustic soda. However, he would have occasion to refer at greater length to this point later in the evening.

Mr. Dyer said he happened to know that Mr. Ogston used litmus-paper that was not bibulous, but painted on one side, and that he laid great stress on that.

Mr. Wrlliams, in reply, said he had not tried congo-red paper, but congo-red solution did not answer the purpose at all. 